\title{
PROF. DR. TAHSIN ÖZGÜÇ
}

(1916-2005)

\section{AYKUT ÇINAROĞLU}

Prof. Dr. Tahsin Özgüç, Ankara Üniversitesi Rektörlüğü sırasında, kurucusu olduğu ve bir süredir tedavi gördüğü A.Ü. Tıp Fakültesi İbn-i Sina Hastanesi'nde, 27.10.2005 günü hayatunı kaybetti.

Prof. Dr. Tahsin Özgüç 1916 yılında Kırcaali'de doğdu. Ankara'da öğrenim gördüğü sırada, Dil ve Tarih-Coğrafya Fakültesi'nin kurulduğu yılda, Arkeoloji Bölümüne kaydoldu ve 1940 yılında mezun oldu. Aynı yıl fakülteye "İlmi Yardımcı" olarak atand.

Prof. Dr. Tahsin Özgüç, 1942-1945 yılları arasında askerlik görevini topçu sınıfında yürütürken bir yandan da doktora çalışmalarına da devam etmiştir. 1942 yılında Doktor unvanını kazandı. Savaş yıllarına denk gelen bu süreç içinde, komutanlığını yaptı̆̆ topçu bataryasının, kimliği belirsiz bir uçağı vurması üzerine, batarya komutanı olarak Özgüç, bir hafta izinle ödüllendirilmişti.

1945-1946 yılları arasında Dil ve Tarih-Coğrafya Fakültesi Arkeoloji asistanı olarak görev yapan Prof. Dr. Tahsin Özgüç, 1946 yılında Doçent oldu. 1954 yılına kadar sürdürdüğü doçentlik görevi sürecinde, Ankara-Anıtkabir Tümülüsleri ve Elbistan Karahöyük kazılarını yürüttü. Aynı zamanda Maltepe-Sivas Kalesi kazılarını da gerçekleştirdi. 1954 yılında Profesörlük unvanin ald.

1948 yılında başlatuğı Kültepe kazılarını, vefat ettiği 2005 yılına kadar kesintisiz sürdürdü. Bu aynı zamanda, Anadolu arkeolojisinde bir rekordur. Kültepe kazıları dışında başka bir Türk arkeoloğu tarafından kesintisiz olarak gerçekleştirilen bir kazı yoktur.

Kültepe kazıları, yalnızca bir arkeolojik kazı değildir. Burası aynı zamanda bir arkeoloji okuludur. Burada yabancı bir çok arkeolog yanında, başta Prof. Dr. Kutlu Emre olmak üzere, Prof. Dr. Aykut Çınaroğlu, Prof. Dr. Hayat Erkanal, Prof. Dr. Armağan Erkanal, Prof. Dr. Aliye Öztan, Prof. Dr. 
Önder Bilgi, merhum Prof. Dr. Uğur Silistreli, Prof. Dr. Fikri Kulakoğlu, Doç. Dr. Tayfun Yildırım, Doç. Dr. Tunç Sipahi, merhum Metin Akyurt ve Rüştü Çetinkaya, Prof. Dr. Tahsin Özgüç'ün arkeolojik kazı yöntemleri ile yoğrulmuşlardır. Akademik yaşantılarını sürdüren bu bilim insanları yanında, çok sayıda arkeoloji öğrencisi de Kültepe kazılarında çalışmışur.

Yukarıda adları dizili Önasya arkeolojisi öğretim üyeleri, günümüzde belli başı kazıların sorumlu başkanlarıdır. Bu öğretim üyeleri bugün, Prof. Dr. Tahsin Özgüç'ün ekolünü, genç nesillere, geleceğin arkeologlarına aktarmaya devam etmektedirler.

Kültepe kazılanı, bir Önasya Arkeolojisi okulu olması yanında, sonuçları ile Anadolu ve Mezopotamya arkeolojisine katkıları da hiçbir zaman yadsınamaz. Özellikle, Kültepe'de açı̆̆a çıkartılan ve sayıları yirmi bini geçen Anadolu'nun en eski yazılı belgeleri olan çivi yazılı Eski Asurca tabletler, çok sayıda yerli ve yabancı filoloğa kitap yazdırmıştur ve yazdıracaktur.

Kültepe kazılarında günışığına çıkartılan çeşitli arkeolojik eserler aynı zamanda, birçok bilim insanının akademik aşamasında, belli başlı malzemeyi oluşturmuştur. Eski Anadolu tarihi ile ilgili her yayında, Kültepe'ye ayrı bir yer verilmiş ve bundan sonrada verilecektir. Başka bir deyişle, eski Anadolu tarihini ya da arkeolojisini yazmak, Kültepe'siz olanaksızdır.

Bunların dışında, Kültepe kazılarında açığa çıkartılan eserler, bugün başta Kayseri Arkeoloji Müzesi olmak üzere, Ankara Anadolu Medeniyetleri Müzesi'nin vitrinlerinin en gözde eserlerini oluşturmaktadır.

Prof. Dr. Tahsin Özgüç, kesintisiz 57 yll devam eden tek Türk kazısı Kültepe'de çalışmalarını sürdürürken, Tokat Erbaa Horoztepe'de, yine Tokat Zile yakınlarında Maşat Höyük'te, Amasya Kazankaya ve Kayseri Develi Fraktin'de kurtarma kazılarını da gerçekleştirmiştir. Bu kazılarda günışı̆ı̆ına çıkarttığı gerek mimarlık eserleri, gerekse küçük eserler Anadolu arkeolojisine projektör büyüklüğünde sşık tutmuştur.

Anadolu arkeolojisi konusunda en fazla makale ve kitap üreten bilim insanı olan Prof. Dr. Tahsin Özgüç, öğrencilerine arkeoloji öğretisi yanında her şeyden önce insan olmayı öğretmeyi düstur edinmiştir.

1968-1969 yılları arasında Dil ve Tarih-Coğrafya Fakültesi dekanlığını yapan Prof. Dr. Tahsin Özgüç, A.Ü. Rektörlüğüne 1969 yılında seçilmiş, rektörlüğün 2 yl süreli olduğu dönemde, tam 6 kez seçim kazanarak 11,5 yl 
kesintisiz A.Ü. Rektörlüğünü sürdürmüștür. Bu da Türk üniversite hayatunda bir rekordu.

Prof.Dr.Tahsin Özgüç adı, her kesimde Prof. Dr. Nimet Özgüç ile birlikte anılmaktadir.

Prof.Dr.Tahsin Özgüç, 1962-1963 yılları arasında the Institute for Advanced Study, Princeton'da, 1964 yllinda Universitat des Saarlandes (Saarbrücken)'de, 1975-1976 ve 1978-1979 yılları arasında Universitat München'da, 1980-1981 ylları arasında The Metropolitan Museum of Art New York'ta misafir ve araşturmacı profesör olarak bulunmuştur.

Avrupa, Amerika Üniversitelerinde, Tokyo Ortadoğu Kültür Merkezi'nde konferans ve seminerler vermiştir.

Prof. Dr. Tahsin Özgüç, 1947-1982 yılları arasında Türk Tarih Kurumu asli üyesi, 1996 yllında ise Türk Tarih Kurumu şeref üyesi olmuştur. 1954 yllında Alman Arkeoloji Enstitüsü (Berlin) üyeliğine, 1969 yllında British Academy şeref üyeliğine, 1976 yilında Amerika Arkeoloji Enstitüsü şeref üyeliğine, 1978 yllında The Society of Antiquaries of London şeref üyeliğine, 1988 yllında Die Bayerische Akademie der Wissenschaften (Münih) üyeliğine, 1996 yılında Türkiye Bilimler Akademisi şeref üyeliğine seçilmiştir.

Prof.Dr.Tahsin Özgüç'e 1980 yılında Doctoris Philosophia Gradum Honoris Causa Ludwig-Maxmilians-Universitaet München, 1989 yllında Rijiksuniversiteit-Gent ve 2001 yllnda Freie Universitaet Berlin tarafindan şeref doktorluğu verilmiştir.

Prof.Dr.Tahsin Özgüç'e 1978 yllında Federal Almanya Cumhuriyeti Büyük Liyakat Haç Nişanı (des Grossen Verdienstfreuzes des Verdienstordens), 1990 yılnda Japonya Doğan Güneş Altun-Gümüş Nişanı (The Order of the Rising Sun, Gold and Silver Star), 1991 ylında Belçika Tacı Ulusal Nişanı (La Décoration d'Officier de I'Ordere de la Couronne), 1992 ylında Collage de France Madalyası, 1992 yilında Türk Tanıtma Vakfi Ödülü, 1996 yılında İş Bankası Ödülü tevcih edilmiştir.

Prof. Dr. Tahsin Özgüç'ün en sevdiği Türk Sanat Müziği şarkısı, "Rabbin Bana Bir Nimeti Varsa O da Sensin"di. 


\section{Arkeolojik Kazalar:}

Ankara Anıtkabir Tümülüsleri

Karahöyük (Elbistan)

Kültepe (Kayseri)

Horoztepe (Tokat)

Maltepe (Sivas) ve Sivas Kalesi

Altuntepe (Erzincan)

Maşat Höyük (Tokat)

Kazankaya (Amasya)

Fraktin (Kayseri)

\section{Yayınlar:}

A: Kitaplar:

1948 Die Bestattungsbraeuche im Vorgeschictliche Anatolien. Veroeffentlichungen der Universitaet von Ankara. 14 Wissenschaftliche Reihe: 5/Ön Tarihte Anadolu'da Ölü Gömme Adetleri. TTKY. VII/17 Ankara.

1950 Kültepe Kazısı 1948/Ausgrabungen in Kültepe 1948 TTKY. V-10 Ankara.

1959 Kültepe-Kaniş. Asur Ticaret Kolonilerinin Merkezinde Yapılan Yeni Araşurmalar/ New Researches at the Center of the Assyrian Trade Colonies. TTKY V-19. Ankara.

1966 Aluntepe I. Mimarlık Anıtları ve Duvar Resimleri/ Architectural Monuments and Wall Paintings TTKY-V/24. Ankara.

1969 Altuntepe II. Mezarlar, Depo Binası ve Fildişi Eserler/Tombs, Storehouse and Ivories. TTKY-V/27. Ankara.

1969 The Hittites. Ankara Turizmi, Eski Eserleri ve Turizmi Sevenler Derneği Yayınları 7. Ankara (1995 Baskısı: Anadolu Medeniyetleri Müzesini Koruma ve Yaşatma Derneği).

1971 Demir Devrinde Kültepe ve Civarı/ Kültepe and Its Vicinity in the Iron Age. TTKY-V. /29. Ankara.

1978 Maşat Höyük Kazılan ve Çevresindeki Araşturmalar /Excavations at Maşathöyük and Investigations in its Vicinity. TTKYV/38, Ankara. 
1982 Maşat Höyük II. Boğazköy'ün Kuzeydoğusunda Bir Hitit Merkezi/ A Hittite Center Northeast of Boğazköy. TTKY V-38a Ankara.

1986 Kültepe-Kanis II Eski Yakındoğu'nun Ticaret Merkezinde Yeni Araşturmalar/ New Researches at the Trading Center of the Ancient Near East. TTKY. V-41. Ankara.

1988 İnandıktepe. Eski Hitit Çağında Önemli Bir Kült Merkezi. An Important Cult Center in the Old Hittite Period. Giriş/Introduction by R.Temizer. TTKY V-43. Ankara.

1999 Kültepe-Kaniş/Neşa Sarayları ve Mabedleri/The Palaces and Temples of Kültepe-Kaniş/Neşa TTKYV.46. Ankara.

2003 Kültepe/Kaniş-Neşa. The Earliest International Trade Center and the Oldest Capital City of the Hittites. The Middle Eastern Culture Center in Japan, İstanbul.

2005 Kültepe/Kaniş-Neşa. The Earliest International Trade Center of the Ancient World and the Oldest Capital Town, Yapı ve Kredi Bankası Yayınlarından.

\section{B. Makaleler:}

1941 “Kurs Vücutlu Kültepe İdolleri” DTCF, Ylllık Araşturma Dergisi I, 1940-1941, s.852-886, Ankara.

1943 "Öntarihte Anadolu İdollerinin Anlam”" DTCF Dergisi II/I, s.65-72.

1944 “Birinci Truva'yı Kim Kurdu?” DTCF Dergisi II/5, s.697-716.

1944 "Yortan Mezarlık Kültürüne Ait Yeni Buluntular" Belleten VIII/29, s.53-70.

1944 “Öntarihte Anadolu Kronolojisi”Belleten IX/35, s.341-360.

1944 “Öntarihte İsparta Ovası Kültürü ve Yeni Buluntuları" DTCF Dergisi II $/ 3$, s.407-418.

1944 "Review of K. Bittel, K. und H.Otto, Eine Vorgeschichtliche Siedlung der Phrygisch Bithynischen V/24, DTCF Dergisi III/1, s.94-100.

1944 "Samsun Hafriyatının 1941-1942 Yll Neticeleri" III. Türk Tarih Kongresi, s.393-419.

1945 "Beypazarı Çevresinden Getirilen Testi ve Damga Mühür" Belleten IX/34, s.289-292.

1945 “Öntarihte Anadolu Yapıları” Arkeoloji Araşturmaları II, No: 47, s.4147. 
1945 "Review of Arif M.Mansel, Trakya-Kırklareli Kubbeli Mezarları ve Sahte Kubbe ve Kemer Problemi”, Belleten IX/36, s.509-518.

1946 “Anadolu'da Arkeoloji Araştırmaları I/ Untersuchungen über Archaeologische Funde aus Anatolien" Belleten X/40, s.557-597.

1946 “Öntarihte Güney ve Güneydoğu Anadolu'nun Mukayeseli Stratigrafisi” DTCF Dergisi IV/2, s.251-264.

1946 “VI. Troia'nın Anadolu Arkeolojisindeki Yeri” Belleten X/37, s.13-28.

1947 'Typical Pottery of the Middle Anatolian 'Copper' and 'Bronze Ages' (New Finds from Kültepe Near Kayseri), Artibus Asiae X/4, s.312-323.

1947 "Türk Tarih Kurumu Adına Yapılan Maltepe Kazısı /Die Grabung von Maltepe bei Sivas" Belleten XI/44, s.641-672.

1947 "Türk Tarih Kurumu ve Sivas İli Adına Topraktepe'de (Sivas Kalesi) Yapılan Kazı/Die Ausgrabungen von Topraktepe der Burg von Sivas", Halil Edhem Hatura Kitabı I, s.219-241, Ankara, TTKYVII/5.

1947 "Eski Hitit Çağının Eşsiz Bir Eseri-Ein einzigartiges Stück aus althethitischer Zeit" Belleten XI/42, s.331-334.

1948 "Elbistan Ovasındaki Tetkik Gezileri ve Karahöyük Kazısı/ Archaeological Journeys in the Plain of Elbistan and the Excavations of Karahöyük", Belleten XII/45, s.226-232/232-237.

1948 “Ankara Üniversitesi Adına Yapılan Fraktin Kazısı ve Tetkik Gezileri/Excavations at Fraktin Near Develi and Researches in Anti-Taurus Region” Belleten XII/45, s. 260-266/266-267.

1948 “Samsun Hafriyatının 1941-1942 Yılı Neticeleri” III. Türk Tarih Kongresi, Ankara 15-20 Kasım 1943, Kongreye Sunulan Tebliğler. TTKY IX-Seri No:3 TTK Basımevi, Ankara, s.393-419.

1950 "Where the Assyrians Built a Commercial Empire in Second Millennium Anatolia: Excavations the Karum of Kaniş" the Illustrated London News, Jan. 4, s.68-71.

1953 "Kültepe'de 1950 Yılında Yapılan Kazılar Hakkında Ön Rapor/Grabung von 1950 in Kültepe" Belleten XVII/65, s.101-122.

1954 "Kültepe'de 1953 Yllında Yapılan Kazılar/Die Grabungen von 1953 in Kültepe", Belleten XVIII/71, s.357-390.

1954 "Koloni Devrinin Geç Safhasına Ait (Ib) Bir Aslan Heykeli Parçası/ Fragment of a Lion Statue in the Late Phase (Ib) of the Colony Period", Belleten XVIII/72, s.441-444/445-447. 
1955 "Kültepe Hafriyatı 1954 Ib Kau Eserleri /Excavations at Kültepe 1954 Finds on Level Ib" Belleten XIX/73 ,s. 55-63/64-72.

1955 "Kültepe Hafriyat 1954 II. Kat Eserleri/ Excavations at Kültepe Level II Finds" Belleten XIX/76, s. 445-452/453-461.

1955 "Koloni Devrinin Geç Safhasına Ait (Ib) Bir Atölye Hakkında/ On a Workshop of the Colony Period Ib" Belleten XIX/73, s.73-80.

1956 "Anitta Hançeri", Belleten XIX/77, s.29-32.

1956 "Fraktin Kabartması Yanındaki Prehistorik Ev/ Prahistorische Haus Beim Felsrelief von Fraktin" Anatolia I, s.59-64.

1957 "The Bitik Vase", Anatolia II, s.57-78.

1958 "Bitik Vazosu" A.Ü.D.T.C.F. Dergisi Cilt XVI Sayı 1-2, s.1-18.

1958 "The Statuette from Horoztepe" Anatolia III, s.53-56.

1959 "A Unique Mother Goddess Statue; a Sistrum; a Bull Standart and "booted" bronzes Tables from Early Bronze Age Anatolia" ILN April 4, s.572-573.

1960 "Monuments of the Period of Taşkın Paşa's Principalty", Atti Del Secondo Congresso Internazionale di Arte Turca, Napoli, s. 197-201.

1961 "Altuntepe Kazları/Excavations at Altuntepe", Belleten XXV/98, s.253-267.

1961 "Kültepe-Kanesh, Mittelpunkt der Assyrischen Handelskonolien in Anatolien", Kunst und Kultur der Hettiter (Eine Ausstellung des Deutcshen Kunstrates e.v., Berlin).

1962 “Mengücüklere Ait Bir Türbe” Milli Birlik Türk Sanat Kongresi 19-24 Ekim 1959, Kongrelere Sunulan Tebliğler, s. 325-324. Ankara.

1963 "An Assyrian Trading Outpost", Sientific American. 208/3, s.96-102; and Reading From: Sientific American Hunters, Farmers and Civilizations: Old World Archaeology, 1979, s.234-241.

1963 "Fouilles Archéologiques effectuées en Anatolia au Cours des Derniéres Années", Synthéses. Revue Internationale, Bruxelles 1963, s.322-331.

1964 "Altuntepe'de Urartu Mimarlık Eserleri/Urartian Architecture on the Summit of Aluntepe" Anatolia VII, (1943), s.43-57.

1964 "The Golden Period of Early Anatolian Art" Hittite Art and the Antiquties of Anatolia Exhibition Catalogue, London, s.46-59. 
1964 "Yeni Araşturmaların Ișı̆̆ında Eski Anadolu Arkeolojisi/ Early Anatolian Archaeology in the Light of Recent Research" Anatolia VII (1963), s.1-42.

1966 "The Art and Architecture of Ancient Kanish" Anatolia VIII (1964), s.27-48.

1966 "Yeni Horoztepe Eserleri/New Finds from Horoztepe" Anatolia VIII (1964), s.19-25.

1967 "Ancient Ararat" Scientific American 216/3, s.38-46.

1969 "Urartu and Altuntepe" Archaeology 22/4, s.256-263.

1974 "A Bronze Hittite Statuette" Anatolian Studies Presented to Hans Gustav Güterbock on the Occasion of His 65 th Birthday, İstanbul, Nederlands Historish-Archaeologish Instituut in Heu Nabije, s.253-255.

1974 "A Bull Shaped Drinking Cup, Discovered in the Vicinity of Kırșehir" Mansel'e Armağan, Ankara, s.963-965.

1974 "Five Vessels Belonging to the Late Phase of the Assyrian Trading Colony Period" Baghdader Mitteilungen 7-Festschrift A.Moortgat, s.149153.

1975 “Atatürk ve Arkeoloji” Cumhuriyetin 50. Ylldönümü Semineri, Türk Tarih Kurumu Basımevi, Ankara, s.109-117.

1975 "Kululu Hakkında Yeni Gözlemler/New Observations on Kululu" Anatollia XVII (1973), s.1-30.

1979 "A Figurine of a God from Anatolia in the Hermitage Museum in Leningrad, Florilegium Anatolicum, Mélanges offerts a Emmanuel Laroche (Paris), E. Doccard, s.291-296.

1979 "Assur Ticaret Kolonileri Çă̆ına Ait İnsan Biçimli Kap/A Vessel in the Form of a Human of the Assryian Trading Colony Period" Belleten XLIII/170, s.261-272.

1980 "Çorum Çevresinde Bulunan Eski Tunç Çağı Eserleri/Some Early Bronze Age Objects from the District of Çorum" Belleten XLIV/173, s.459-474.

1980 "Excavations at the Hittite Site, Maşathöyük" AJA 84, s.305-309.

1982 "Atatürk et I'Archéologia, Mémorial Atatürk (Traduit par H.Gonnet), Études D'Archéologie et de Philologie Anatoliennes” Institut Français D'Etudes Anatoliennes, Paris, s.5-12. 
1983 "Jewellery, Gold Votive Plaques and a Silver Belt from Aluntepe" Anatolian Studies 33, s.33-37.

1983 "Les Cultures Anatoliennes" Forum Conseil de I'Europe, Civilisations Anatoliennes, V-VII.

1983 "New Finds From Kanesh and What They Mean for Hittite Art" Festchrift für Kurt Bittel, Mainz-am Rhein, Philipp von Zabern, s.421426.

1983 "Some Rare Objects from Karum of Kanish, Kani..uwar", A Tribute to Hans G.Güterbock on his Seventy Fifth Birthday. The Oriental Institut of the University of Chicago. Assyriological Studies No:23, s.173-178.

1986 "Ferzant Hitit Mezarlığı Hakkında Yeni Gözlemler/ The Hittite Cemetery at Ferzant: New Observations on the Finds" Belleten L/ 197, s.383-402.

1986 "Glazed Faience Objects from Kanish" in Bibliotheca Mesopotamica Vol.21 Insight Through Images. Studies in Honour of Edith Porada. Edited by Marilyn Kelly-Buncellati in Collobration with Paolo Matthiea and Maurits von Loon. s. 201-208.

1986 "New Observations on the Relationship of a Kültepe with Southeast Anatolia and North Syria During the Third Millenium B.C." Ancient Anatolia, Aspects of Charges and Cultural Development, Essays in Honour of Machteld J. Mellink, The University of Wisconsin Press, s. $31-47$.

1988 "Kültepe and Anatolian Archaeology Relating to the Old Assyrian Period" Essays on Anatolian Studies in the Second Millenium B.C. BMEECJ IV s. 1-9.

1989 "Maşathöyük" Reallexikon der Assyiologie und Vorderasiatischen Archaeologie 7, s.444-446.

1991 "The Newly Discovered Cult Objects from the Karum of Kanesh" BMEECJ V, s.319-334.

1992 "An Antropomorphic Vase from Karum of Kanesh" Hittite and Other Anatolian and Near Eastern Studies in Honour of Sedat Alp, Sedat Alp'a Armağan/Festschrift für Sedat Alp, Edited by H. Otten et. al. Anadolu Medeniyetlerini Araşturma ve Tanıtma Vakfı Yayınları sayı 1. Türk Tarih Kurumu Basımevi, Ankara, s.425-428. 
1992 "New Glazed Faience Objects From Kanish" von Uruk nach Tutul, Festschrift für E. Strommenger, München s. 159-162.

1993 "Studies on Hittite Relief Vases, Seals, Figurines and Rock Carvings" Nimet Özgüç'e Armağan, Aspects of Art and Iconography: Anatolia and Its Neighbors, Studies in Honour of Nimet Özgüç. Edited by M.J.Mellink et al. TTK Basımevi Ankara, s. 473-499.

1993 "Eskiyapar Treasure" Nimet Özgüç'e Armağan Aspects of Art and Iconography: Anatolia and Its Neighbors, Studies in Honour of Nimet Özgüç. Edited by M.J.Mellink et al. TTK Basımevi Ankara, s.

1993 “Temples of Kanish" Ist Mitt. 43 (Festchrift für P.Neve), s.167-174.

1994 "A Cult Vessel Discovered at Kanish" Beitrage zur Altorientalischen Archaologie und Altertumskunde" Festschrift für Barthel Hrouda zum 65. Geburtstag. Herausgegeben von P. Calmeyer, K.Hecker, L.J.Rost, C.B.F. Walker, Wiesbaden, s.221-227.

1994 "A Votive Foundation-Nail in the Temple of Maşathöyük" Altertumskunde des Vorderen Orients Band 4. Beschreiben und Deuten in der Archaologie des Alten Orients, Feschrift für Ruth Mayer-Opificius, s.227-234.

1995 "Two Eagle-Shaped Cult Vessels Discovered at Kanish" Beitrage zur Kulturgeschichte Vorderasiens: Festschrift für Rainer Michael Boehmer, con U. Finkbeiner et al. Mainz am Rhein, s.521-526.

1996 "A Boat-Shaped Cult-Vessel from the Karum of Kanish" Mezopotamian History and Environment. Occasional Publications Nol II. Cinquante-deux Reflezions sur le Proche-Orient Ancien. Offertes en Hommage a Leon de Meyer. Printed by Oreantaliste, Klein Dalenstraat 42, B-3020 Herent, s.369-375.

1996 "Two Antelope-Shaped Cult Vessels Discovered at Kanish" Ist Mitt 46 (Festschrift für K. Tuchelt) s. 61-66.

1996 "An Old Babylonian Cylinder Seal from Alaca Höyük" Altertumskunde des Vorderen Orients Band 7. Vom Halys zum Euphrat. Thomas Beran zu Ehren s. 211-214.

1996 "An Obsidian Storehouse Close to the Temples Built by Anitta King of Neşa" Collectanea Orientalia. Historie, Arts de L'espace et Industrie de la Tere. Etudes Offertes en Hommage a Angés Spycket. Civili- 
sations Du Proche-Orient. Serie I. Archeologie et Environnement Vol:3, s.279-283.

1998 "Boar-Shaped Cult Vessels and Funeral Objects at Kaniş" Altorientalische Forschungen Band 25 (Festschrift für H.Klengel), s. 247-256.

1998 “Kululu'da Yeni Bulunmuş Bir Sfenks Başı ve Yazıt Parçası" Light on Top of the Black Hill Studies Presented to Halet Cambel (ed. G. Arsebük, M.J.Mellink,W.Schirmer) İstanbul, s.615-618.

1999 "Karum Kanish as a City of International Trade" Çağlar Boyunca Anadolu'da Yerleşim ve Konut Uluslararası Sempozyumu, International Symposium on Settlement and Housing in Anatolia Through the Ages. Ege Yayınları, s.321-330.

1999 "Vases used for Ritual Purposes from Eskiyapar" BMEECJ XI, s.1-22.

1999 “The Metal Figurines for two Hittite Gods" BMEECJ XI, s.23-38.

2000 "Kanish-Neşa, The Earliest International Trade Center of the Near East" in Proceedings of the First International Congress on the Archaeology of the Ancient Near East. Rome May 18 th-23rd 1998 (Ed. Matthiae, P. Enea, A., Peuronel, L.,Pinnock, F.) Roma.

2002 "Kurator". Die Hethiter und Ihr Reich. Katalog. Kunst-und Ausstellungshalle der Bundesrepublik Deutschland 18. Januar-28 April 2002.

2002 "Frühe Bronzezeit" Die Hethiter und Ihr Reich. Katalog. Kunst-und Ausstellungshalle der Bundesrepublik Deutschland 18. Januar-28 April 2002, s.36-45.

2002 "Die Stellung der Hethiter im Kulturellen Erbe der Turkei" Die Hethiter und Ihr Reich. Katalog Kunst-und Ausstellungshalle der Bundersrepublik Deutschland 18. Januar-28 April 2002, s.14-15.

2002 "Anatolische Fürstensitze" Die Hethiter und Ihr Reich. Katalog. Kunst-und Ausstellungshalle der Bundersrepublik Deutschland 18. Januar-28 April 2002, s.42-45

2002 "Opfer und Libation" Die Hethiter und Ihr Reich, Katalog. Kunst-und Ausstellungshalle der Bundersrepublik Deutschland 18. Januar-28 April 2002, s.122-127.

2002 "Karum-Zeitliche Kultgefasse" Die Hethiter und Ihr Reich, Katalof. Kunst-und Ausstellungshalle der Bundersrepublik Deutschland 18. Januar-28 April 2002,s.128-133. 
2002 "Neşa" Die Hethiter und Ihr Reich, Katalog. Kunst-und Ausstellungshalle der Bundersrepublik Deutschland 18. Januar-28 April 2002,s. 152-155.

2002 "Maşathöyük" Die Hethiter und Ihr Reich, Katalog. Kunst-und Ausstellungshalle der Bundersrepublik Deutschland 18. Januar-28 April 2002,s.168-171.

2002 "Alaca Höyük" Die Hethiter und Ihr Reich, Katalog. Kunst-und Ausstellungshalle der Bundersrepublik Deutschland 18. Januar-28 April 2002,s.172-175.

2002 "Frühe Zeugnisse Religiöser Volkkunst" Die Hethiter und Ihr Reich, Katalog. Kunst-und Ausstellungshalle der Bundersrepublik Deutschland 18. Januar-28 April 2002,s. 240-243.

2002 "Die Keramik der Althethitischen Zeit" Die Hethiter und Ihr Reich, Katalog. Kunst-und Ausstellungshalle der Bundersrepublik Deutschland 18. januar-28 April 2002,s. 248-255.

\section{A: Kitaplar}

Ortak Yayınlar:

1949 (Nimet Özgüç ile birlikte) Türk Tarih Kurumu Tarafından Yapılan Karahöyük Hafriyatu Raporu 1947 /Ausgrabungen in Karahöyük 1947, TTKYV-7 Ankara.

1953 (Nimet Özgüç ile birlikte) Türk Tarih Kurumu Tarafindan Yapılan Kültepe Kazısı Raporu 1949/ Ausgrabungen in Kültepe Bericht über die im Auftrage der Türkischen Historischen Gesellschaft, 1919 durchgeführten Ausgrabungen. TTKYV-12, Ankara.

1958 (M.Akok ile birlikte) Horoztepe: Eski Tunç Devri Mezarlı̆̆ı ve İskan Yeri/An Early Bronze Age Settlement and Cemetery TTKYV/18, Ankara.

1965 (S.K.Yetkin, F. Sümer, H.Z. Ülken, N. Çağatay, H. Karamağralı ile birlikte) Turkish Architecture, the Institute of History of Turkish and Islamic Arts. Faculty of Divinity, Ankara University Publication No: 62.

\section{B: Makaleler:}

1941 (Ş.A. Kansu ile birlikte) "Antropoloji Enstitüsünde Muhafaza Edilmekte Bulunan Bazı Prehistorik Arkeoloji Eşyası" Belleten VI/19, s.255-260. 
1945 (N.Özgüç, K.Kökten ile birlikte) "1940 ve 1941 Yilında Türk Tarih Kurumu Adına Yapılan Samsun Bölgesi Kazıları Hakkında İlk Kısa Rapor" Belleten IX/35, s.361-400.

1947 (M.Akok ile birlikte) "Türk Tarih Kurumu Adına Anıtkabir Alanında Yapılan Tümülüs Kazıları /Ausgrabungen an Zwei Tumuli auf dem Mousaleumshügel bei Ankara" Belleten X/41, s.27-56.

1948 (Nimet Özgüç ile birlikte) "A Birthplace of the Hittite Empire: The Karum of Kanesh, an Ancient Anatolian Trade-Center" The Illustrated London News, Dec. 18, 1948, s.701-703.

1954 (M.Akok ile birlikte) "Melik-Gazi Türbesi ve Kalesi" Belleten XVIII/71, s. 331-336, Ankara.

1955 (M.Akok ile birlikte) "Develi Abideleri" Belleten XIX/75, s.377-394, Ankara.

1956 (M.Akok ile birlikte) "Sarnhan" Belleten XX/79 s. 379-383, Ankara.

1956 (M.Akok ile birlikte) "Ağzıkara Han" Yıllık Araştırmalar Dergisi, Sayı 1, s.93-104, Ankara.

1957 (M.Akok ile birlikte) "Alayhan, Öresunhan ve Hızırilyas Köşkü” Belleten XXI/81, s.139-148, Ankara.

1957 (M.Akok ile birlikte) "Horoztepe Eserleri/Objects from Horoztepe" Belleten XXI/82, s.201-209/211-219.

1958 (M.Akok ile birlikte) "Üç Selçuklu Abidesi: Dolayhan, Kesikköprü Kervansarayı ve Han Camii" Belleten XXII/86, s.251-259., Ankara.

1958 (M.Akok ile birlikte) "Afşin Yakınındaki Eshab-ı Kehf Külliyesi" İlahiyat Fakültesi, Türk ve İslam Sanatları Tarihi Enstitüsü, s.77-87, Ankara.

1984 (T. Saatçi ile birlikte) "Altuntepe'de Bulunmuş olan Emevi Sikkeleri/Altuntepe Definesi” Belleten LVII/188, s.1191-1205, Ankara. 
